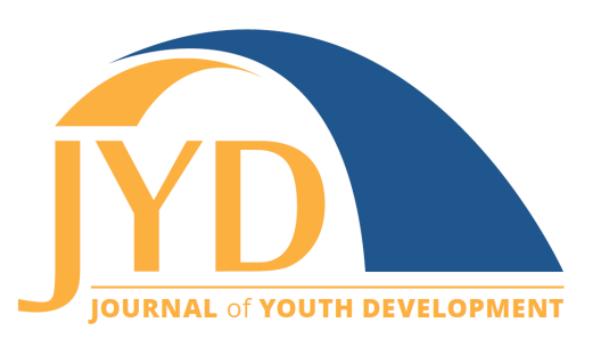

http://jyd.pitt.edu/ | Vol. 16 Issue 2-3 DOI 10.5195/jyd.2021.1045 | ISSN 2325-4017 (online)

\title{
Management and Governance Accountability to Children: Participation and Representation in Organisational Decision Making
}

\author{
Claire O'Kane \\ Independent Consultant \\ claireokane2008@gmail.com
}

Annabel Trapp

Independent Consultant

mail@annabeltrapp.net

Paul Stephenson

World Vision International

paul_stephenson@wvi.org

Julia Smith-Brake

World Vision International

julia_smith-brake@wvi.org

\begin{abstract}
Children's participation and accountability to children are increasingly common aspirations of childfocused organisations; development agencies and research institutions frequently use young people's advisory councils as one path to participation. A key challenge is to not only find meaningful ways to institutionalise children's views as part of organisational decision making, but also to identify and address barriers to participation. This article presents the findings of a commissioned landscape assessment to identify good practices and lessons learned from child-focused agencies, in order to inform the operationalisation of children's requests on programme improvements and accountability to children. The study was exploratory and qualitative. It included primary and secondary data collection, including a desk review, key informant interviews with adults and young people, and focus group discussions with young people. The findings showed common elements of organisational models of child participation and insights from children and young people on the types of decisions they want to influence, reasons why they should be heard, and how-to approaches to support their meaningful participation. Other findings focused on key challenges of children's participation in governance, including adult mindsets, low capacity, and structural restrictions, and lessons learned on enabling factors, such as organisation-wide buy-in, and space and inclusion for children and young people. Further inquiry could inform the purpose,
\end{abstract}

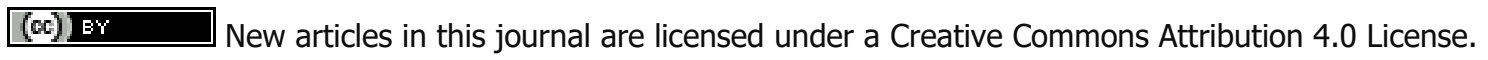
This journal is published by the University Library System, University of Pittsburgh and is cosponsored by the University of Pittsburgh Press. The Journal of Youth Development is the official peer-reviewed publication of the National Association of Extension 4-H Youth Development Professionals and the National AfterSchool Association. 
Journal of Youth Development | http://jyd.pitt.edu/ | Vol. 16 Issue 2-3 DOI 10.5195/jyd.2021.1045

Management and Accountability to Children

scope, and appropriateness of child participation in governance structures within child-focused organisations.

Key words: child participation, accountability to children, inclusive governance, child participatory research

\section{Background}

Children's participation and accountability to children are increasingly common aspirations of child-focused organisations, though they remain largely elusive concepts. Participation can include information-sharing, dialogue, and process engagement, but can also risk challenges such as tokenism and selective inclusion (Tisdall, 2015). Despite good intentions, adults can inhibit child participation. Adult-created participatory processes can allow for participation in decision making, while still prohibiting the power to make real change. Charles \& Haines (2019) found that young people engaged in participatory decision making felt their contributions remained largely unseen and unrecognised by adults (see also Lundy, 2007; Wyness, 2009).

Lundy (2007) proposed a new model for conceptualising Article 12 of the UNCRC ${ }^{1}$ which focuses on four elements of operationalising child participation:

1. Space: Children must be given the opportunity to express a view

2. Voice: Children must be facilitated to express their views

3. Audience: The view must be listened to

4. Influence: The view must be acted upon, as appropriate (p. 933).

"While Lundy's conceptualisation has been widely welcomed in research, policy and practice, there is a dearth of examples in the literature regarding how the concepts of space, voice, audience and influence can be operationalised" (Kennan et al., 2019, p. 205). Development agencies and research institutions increasingly use young people's advisory councils as one path

${ }^{1}$ Article 12 of the United Nations Convention on the Rights of the Child stipulates:

1. States Parties shall assure to the child who is capable of forming his or her own views the right to express those views freely in all matters affecting the child, the views of the child being given due weight in accordance with the age and maturity of the child.

2. For this purpose, the child shall in particular be provided the opportunity to be heard in any judicial and administrative proceedings affecting the child, either directly, or through a representative or an appropriate body, in a manner consistent with the procedural rules of national law.

(United Nations Committee on the Rights of the Child, 2009, p. 3) 


\section{Management and Accountability to Children}

to participation. Collins et al. (2020) found young people's advisory councils contribute an important element to research practice, and open dialogue with young people can support meaningful participation; on the other hand, they also found young people and adults often have differing expectations of advisory council roles.

A key challenge is not only to find meaningful ways to institutionalise children's views as part of organisational decision making, but also to identify and address barriers to participation and feedback to children on how their views are being considered and put into practice (Tisdall, 2015). In line with World Vision International's strategic direction for child participation, the organisation has piloted and strengthened a Children's Feedback Mechanism at national levels to enable children's views to influence programme improvements and enhanced accountability to children.

At higher levels, management supported children's representation in the Triennial Council, World Vision's highest governance body, which meets every 3 years and includes representatives from 53 national boards and advisory councils, global leaders, national directors, and the international board. In preparation for the November 2019 Triennial Council, children's representatives reviewed the recommendations from children in the previous Triennial Council and were given the opportunity to develop their own requests, which they presented to leadership:

1. Ensure that children's participation is central to World Vision's work.

2. Create more spaces for children to be listened to and consider the different perspectives they can offer.

3. Establish children's consultative councils at the national and global level to ensure they can provide views and opinions on issues relevant to them.

4. Promote more visits of World Vision leaders to communities to meet children and get their views directly.

Taken together, these requests provide an opportunity for World Vision to take the next steps in engaging and listening to children in ways that are meaningful to them and to the organisation.

The main purpose of this article is to present findings of the landscape assessment commissioned by World Vision management, identifying good practices and lessons learned both internally and from other child-focused agencies, in order to inform the operationalisation of children's requests on programme improvements and accountability to children. Using an 


\section{Management and Accountability to Children}

adapted version of Lundy's participation framework, the landscape review is used to offer a meaningful alternative to a top-down institutional youth advisory council, providing recommendations that intentionally counter tokenism and promote useful and meaningful participation at all levels of organisational decision making. Other child-focused agencies that were consulted in the landscape assessment included Child Helpline International, Child Rights Connect, Plan International, Queen's University Belfast, Ryerson University Toronto, Save the Children UK, and terre des hommes Germany.

\section{Methodology}

To identify best practices on how to implement children's requests to strengthen children's decision making at program, management, and governance levels, World Vision International (WVI) conducted a landscape analysis on its own programming and other international childfocused agencies.

The study was exploratory and qualitative. Primary and secondary data collection was undertaken. A desk review of over 40 publications and organisational documents was followed by 26 key informant interviews (KIIs) with adults and young people and focus group discussions (FGDs) with 56 young people. Lundy's (2007) model for meaningful participation was adapted for this study to collect and analyse the data.

A total of 82 individuals participated. Perspectives were heard from young people (aged 10 to 17 years) and adults in six case study countries.

In KIIs and FGDs, purposeful sampling was used to identify and select study participants. Specific variables were used to select participants, such as age, gender, and ethnicity, with targeted efforts to learn from young people, especially marginalised children, who have been actively engaged in existing WVI programmes and structures. Child participants included children with disabilities, children living with relatives, children from single-parent families, and children affected by conflict and insecurity.

KII participants consisted of adults and young people's representatives actively engaged in the programme's processes or structures, supporting children's participation in organisational decision making. Interviews were conducted by phone. FGDs with young people participating in WVI programmes as members of children's clubs, consultative committees, student parliaments, 
and/or child youth movements were facilitated and documented by local staff. In three countries (Dominican Republic, Ghana, and Palestine), FGDs were conducted in person using visual, participatory tools. In Romania, the same interview tool was used in an online meeting format with members of WVI Romania Children's Consultative Committee residing in different regions of the country.

TABLE 1. Participant by Country and Subgroup

\begin{tabular}{|l|c|c|c|c|c|}
\hline Subgroup & Key informants & Focus groups & Total \\
\hline & Female & Male & Female & Male & \\
\hline $\begin{array}{l}\text { Dominican Republic child/youth participants (10-17 } \\
\text { years) }\end{array}$ & & & 12 & 6 & 18 \\
\hline Ghana child/youth participants (10-17 years) & 1 & & 14 & 6 & 21 \\
\hline Peru child/youth participants (15-17 years) & 2 & 1 & & & 3 \\
\hline Palestine youth participants (15-17 years) & & & 6 & 5 & 11 \\
\hline Romania youth participants (15-17 years) & 1 & & 6 & 1 & 8 \\
\hline Philippines youth participant (17 years) & & 1 & & & 1 \\
\hline World Vision (staff/leaders) & 7 & 5 & & & 12 \\
\hline Other organizations (staff/leaders) & 6 & 2 & & & 8 \\
\hline Total participants & $\mathbf{1 7}$ & $\mathbf{9}$ & $\mathbf{3 8}$ & $\mathbf{1 8}$ & $\mathbf{8 2}$ \\
\hline
\end{tabular}

Study tools based on tried and tested methods were translated into local languages, and local facilitators were mentored in effective use of the tools by the lead researcher. Interviews were conducted by the lead researchers, or by others under the supervision of lead researchers. All participants received information about the research. Informed consent was sought from all participants after informing them that there would be no adverse or beneficial consequences to their relationship with World Vision as a result or decision to participate and that they could withdraw at any stage of the process. No research participants, including World Vision staff and other organizations, are identified in the research results or publications. For respondents 18 years and under, consent was gained from their parent or guardian, and assent was gained from the child/young person.

All data was entered, processed, and thematically analysed using MS Excel and NVivo software. Template analysis was applied to support systematic thematic analysis, while seeking to balance flexibility and structure (King \& Brooks, 2017). Central to template analysis is the development 


\section{Management and Accountability to Children}

of a coding template, which summarises themes identified by the researcher(s) as important in a data set, organising them in a meaningful manner. Drawing upon an adapted version of Lundy's (2007) model for meaningful participation, data was gathered and analysed under eight main themes: (a) Spaces, (b) Opportunities, (c) Capabilities, (d) Influence, (e) Lessons learned, (f) Monitoring, (g) Recommendations, and (h) Other comments. The codes were then elaborated and adapted in a flexible manner to identify and categorise emergent themes and sub-themes while coding qualitative data from the desk review, KIIs, and FGDs in the NVivo program. Data triangulation was used during the analysis by cross-checking data from primary and secondary sources. ${ }^{2}$ The purpose of analysis was not to compile a formative quantitative view of findings, but to transfer the themes of children's participation into observations on challenges, enabling factors, and children's priorities for their own participation with the intention of operationalising meaningful participation in governance.

\section{Key Findings}

This section presents findings from the desk review, KIIs, and FGDs. The section is structured into the most prevalent and salient themes, reflecting findings across organisations and from the broader literature from the desk review. The four key thematic categories that arose included essential elements of child participation in governance of different organisational models, findings on challenges to children's participation in decision making and governance, lessons learned on enabling factors, and children's perspectives on decision making.

\section{Key Elements of Organisational Models}

Meaningful participation of children and young people in organisational decision making and governance requires organisational commitment and strategies supporting processes and platforms for children and young people to access information and express their views. In qualitative interviews, an international expert noted, "In my opinion, there is no right answer on how children can be involved in governance. It really depends on resources, context, and where staff are at. If an organisation is advanced with resources on child participation, then you have a head start."

\footnotetext{
${ }^{2}$ See Appendix 2 for Coding Template and main "Node" structure.
} 


\section{Management and Accountability to Children}

Based on triangulation of data from both the desk review and primary data collection among organisational representatives, the study revealed the following are often included in organizational models of children's participation:

1. structures for children and young people's participation in governance such as a child advisory committee;

2. capacity building of adults to create enabling environments;

3. children's dialogue and representation with senior management on boards at local and/or global levels;

4. organisational strategies focusing on children's participation in governance, supported by policies, resource allocation, child-friendly information, quality standards, and staff training;

5. child-friendly accountability mechanisms to ensure that children and young people are able to provide feedback on decisions affecting them, and to ensure feedback is provided to young people about decisions made;

6. capacity building of children and young people to strengthen knowledge, skills, and confidence to express their views and influence decisions affecting them; and

7. support for child-led groups.

The case study below exemplifies many of these common elements found in organisational models of child participation in governance.

\section{Case study: Global Youth Advisory Panel, Plan International}

Building upon existing good practice at national levels, in 2013 Plan International developed a strategy to scale up children and young people's participation in organisational decision making. The strategy was developed and approved in the Members Assembly-the highest level of decision making. The strategy encouraged the formation of youth advisory panels at national levels, with opportunities for youth representatives to participate in management forums. A global youth advisory panel (GYAP) was also formed with elected representatives from some of the national level youth advisory panels.

The GYAP brought together nine young people aged 12 to 24 years; five representatives were from different regions (one per region), plus four spaces for young people from national organisations (in fundraising countries). Each young person was elected for a term of 3 years but was asked to step down once they reached the age of 24 years. The GYAP held a face-toface global meeting once a year, and regular skype calls were organised during the year. Two members of the GYAP participated in the Members Assembly twice a year, one as a participant, 


\section{Management and Accountability to Children}

and one as an observer (who would then participate in the following meeting). Robust child safeguarding procedures were applied.

From 2014 to 2018 the GYAP's priorities included

- taking part in meetings with the Members' Assembly and the International Board providing insights and new perspectives on the global strategy and on global initiatives;

- $\quad$ providing guidance to staff on working with young people;

- supporting the development of national panels of youth advisors; and

- contributing to the development and co-facilitation of online training modules for staff on "working with children as partners."

\section{Lessons Learned}

- Prepare and train adults: Significant preparations of adults and flexibility to adapt formal ways of working is required to help create a child-friendly enabling environment. The online training module "working with children as partners" was appreciated by staff.

- Ensure child-friendly information: The development and dissemination of child friendly information is required to support informed and meaningful participation of young people.

- Time constraints: Time constraints of young people and logistical challenges around different time zones and different languages create significant challenges in organising regular online calls with GYAP members. It is especially hard to connect and actively engage young people living in rural areas who have less access to Internet, and who may require a translator to contribute.

- Identify relevant decision makers: It is necessary to analyse which decisions children and young people want to influence, and to analyse who makes these decisions in order for young people to meet and dialogue with the most relevant organisational decision makers.

- Consider sustainability from the outset: It is important to have adequate human and financial resources to sustain a global level mechanism in the long-term.

\section{Findings on Key Challenges}

\section{Organisational and Individual Mindset and Capacity}

International organisations tend to be hierarchical in their decision making structures and processes, creating barriers to children's influence on decisions affecting them (World Vision, 


\section{Management and Accountability to Children}

2014). When there is no high-level mandate to engage children in organisational decision making and governance, it is often ad-hoc, dependent on individual motivation rather than strategic prioritisation and support. Lundy (2018) stated, "If [children's participation] cannot be achieved meaningfully, then it appears to be considered legitimate to not do it at all. From a human rights perspective, this is truly striking. It is difficult to think of another situation where it would be presented as honorable to deny an individual the enjoyment of their rights on the basis that full compliance is impossible" (p. 346).

Across diverse socio-cultural contexts, adult mindsets and cultural norms are barriers to children's participation, as girls and boys are not recognised as social actors who should influence decisions, and children's capacities are underestimated (Blanchet Cohen \& Torres 2015; Charles \& Haines, 2019; Hinton, 2008; Theis, 2007; World Vision Bangladesh, 2018). As a result, if insufficient efforts are made to prepare and train adult staff, and to sensitise parents and community leaders, there are increased risks of unsafe and/or tokenistic participation of children and young people. A senior advisor commented, "The main challenge we face is the mindset of adults-the traditional views of children in families, communities and institutions. We need to have policies that mandate and support capacity-building for adults, especially for staff members."

Different agency staff reflected that varied levels of support and training provided to children's representatives in different contexts created challenges when children came together at the global level. Some children were well informed, prepared, and supported, but others less so. Tsang et al. (2020) also reflect on discrepancies in training received by children, which contributed to mixed results.

\section{Ethical and Logistical Challenges}

Commonly arising ethical issues faced when engaging children and young people in organisational decision making and governance include safeguarding concerns and efforts to balance children's participation and protection. Second, there are concerns around exclusion and processes that support privileges for a few. Third, managing time constraints and expectations of children and adults-including issues around informed consent and compensation: young people face significant time constraints to participate in organisational processes, as they are often juggling education, leisure activities, and unpaid and paid work responsibilities. Furthermore, requesting children to take on too many organisational 


\section{Management and Accountability to Children}

responsibilities raises ethical concerns relating to work and compensation for their time (Gruber \& Gyurko, 2018; O’Kane \& Barros, 2019).

Supporting global-level children's advisory structures and processes introduces a number of logistical challenges; for example, working across different time zones and languages (Collins et al., 2020). At national and local levels logistic challenges are also experienced, particularly when efforts are made to reach and include children and young people from rural and remote communities that may lack Internet access. It can also be logistically and administratively challenging to arrange meetings at times that are convenient to all. Organisational jargon and acronyms create additional challenges when developing and using child-friendly language. Formal Board and/or management meetings also create barriers to meaningful participation of children (Save the Children, 2010).

\section{Structural and Sustainability Challenges}

Organisations have faced challenges in sustaining global children's advisory structures, as they tend to be resource-heavy in terms of necessary human, material, and financial resources to support quality processes. A senior advisor from a child-focused agency mentioned, "There was some funding for [children's participation in organisational structures] for a few years, but when the funding stopped the momentum stopped." Global children's advisory structures are harder to sustain when they are initiated at the global level, dependent on short-term funding, lack broader organisational policies to ensure budget allocations, and lack child involvement in the design and implementation.

Lundy (2007) emphasised the importance of children being able to influence decisions affecting them. However, some organisational efforts to support children's participation in governance have described how it can be challenging to determine the level of children's influence on decisions, even if they are present in high-level meetings and governance structures (Save the Children, 2009, 2010). Unclear outcomes in terms of children's influence make it more challenging to provide concrete feedback to children, thus reducing accountability to children. Power dynamics, both overt and covert, are at play in organisational decision making, which create challenges to meaningful and transparent participation of young people (Arunkumar et al., 2018; Collins et al., 2020; Hinton, 2008; Lundy, 2018).

Structures and processes for children's participation in organisational governance are harder to sustain when there is a lack of clarity on the scope and purpose. Challenges concerning mutual 


\section{Management and Accountability to Children}

expectations of children and adults are also harder to meet when there is insufficient shared understanding about the roles and power of children and young people in management and governance. It is critically important to understand how and where organisational decisions are made, and to be transparent with children and young people about which decisions they are able to influence. For example, it may not be the most effective use of organisational resources, nor children's time and efforts, for children to primarily meet with board members, if board members are not the ones developing organisational strategies, programmes, and plans.

Despite intentions for global level children's advisory committees to build upon local structures, if the planning starts by focusing on the global level, it is harder to develop strong linkages with local-level child participation processes. When linkages are weak between global advisory structures and children at national and local levels, it creates sustainability challenges and weaknesses in ensuring accountable feedback to children at local levels. A senior manager of a child-focused agency stated, "In an ideal world we would build up from the local to the global rather than the other way around. We have way too many examples that top-down approaches do not work in development work. If I did it again, I would probably prioritise the national level [to strengthen linkages]."

\section{Lessons Learned on Enabling Factors}

\section{Organisational Buy-In, Resources, and Processes}

Meaningful participation of children in organisational decision making and governance requires a high-level mandate. Senior managers who believe in children's rights and capacities as social actors are more able to institutionalise children's participation in organisational decision making. One NGO advisor emphasised, "In all examples of successful and meaningful engagement there has been top-level management leadership." The desk review further revealed that senior leaders have the power to develop and operationalise strategies and budget allocations to support sustainable and good quality processes for children's participation (Adolescent Health Initiative 2014; Elsley \& Tisdall, 2014; World Vision Romania, 2013; World Vision, 2019). Organisation-wide buy-in and capacity building of staff is necessary to foster commitment to listen and respond meaningfully to children's views.

Children's participation in organisational decision making at all levels tends to be more effective when it builds upon existing good practices at the local and national levels, such as communitybased child clubs, peer groups, school councils, and child networks. Existing children's 


\section{Management and Accountability to Children}

collectives provide structures and spaces for children and young people to elect their own representatives to be part of governance matters that affect them at different levels of decision making. Where there is an existing organisational culture supporting children's participation in programming and experienced and committed management and field staff, there are increased opportunities to build meaningful participation into organisational management and governance (see the case study below on World Vision Romania's experience with their national children's consultative committee).

Quality participation requires dedicated resources in staff time and budgets (Lundy 2018; Tisdall, 2015). Children's participation requires investments in processes over time, building children's knowledge, skills, and confidence, as well as prior investments in staff preparations and the development and dissemination of child-friendly information and child-friendly tools. Additionally, virtual communications are increasingly available and feasible across geographies and time zones, proving valued contributions to increasing inclusion (Collins et al., 2020). When developing accessible information and tools, it is necessary to ensure budgets to adapt materials for children and young people of different ages and abilities. A senior advisor explained, "We need to ensure resources for staff and operations. This is critical to make the child participation standards and principles compulsory, rather than recommendations."

Especially when working with the most vulnerable children, quality participation requires investments in processes that enable children to develop relationships and trust, to gain knowledge, skills, and confidence, and to have genuine space to discuss and analyse priority issues affecting them (Collins et al., 2020; Save the Children UK, 2010; Tsang et al., 2020; UNICEF, 2020). Flexibility and responsiveness are also required by adults and organisations to ensure relevant, respectful, and accountable participation of children. Regular structured interactions between children and adults enable trust, relationship building, influence, and accountability (Adolescent Health Initiative, 2014; Arunkumar et al., 2018; Eurochild 2017; Gruber \& Gyurko, 2018; Save the Children UK, 2009, 2010; World Vision, 2015). A senior manager stated that most important was the quality of support that children received: using standards to guide interactions, ensuring children were properly informed, safeguarding, and preparation of children and adults.

\section{Case study: Children's Consultative Committee, World Vision Romania (WVR)}

In 2012 a regional grant enabled WVR to establish local children's initiative groups in one area development programme (ADP). The Youth Empowerment Programme (YEP) Coordinator takes 


\section{Management and Accountability to Children}

up the story: "In 2012 we started creating bases for youth empowerment in one ADP. Groups of children were taught how to identify community problems, find solutions and create a working plan in order to address these. Then to work with adults and create bridges with the local authorities. From this experience and children's leadership we decided to create a national group of children who have a role to consult children from rural areas and to lift it to the national leadership."

Over time, the group connected across different ADPs with a focus on encouraging intergenerational dialogue and partnering between adults and children to solve community issues. This created a culture of participation that now informs all programming decision making.

Following the Triennial Council meetings in 2013, the WVR leadership decided to push the boundaries further and set up a Children's Consultative Council (CCC) at the national level. Building on the strong networks at the local and county level, the CCC aimed to engage creatively with senior leadership and the Board to systematize the flow of information and interaction between young people and adults to exchange ideas for decision making.

The CCC provides a conduit for children to share their needs, priorities and ideas to donors, senior management, board members, and other WV ambassadors. Children serve for 2 years on the CCC and are selected by their peers. They meet face-to-face twice a year for a time of mutual learning and planning. Children also have the opportunity to share ideas on strategic plans or initiatives.

\section{Lessons Learned}

The success for this process was that we started from the community level with existing structures and initiatives, and each year we invite [add] a bit to have children's structures at the country and national level. (YEP, coordinator)

- Adult support: Staff whose role includes dedicated time focused on child participation in each ADP. It takes a lot of time to provide child-friendly information and to ensure their views are shared with the leadership. WV staff members, teachers, and board members-all need to know how to engage with and listen to children effectively. 


\section{Management and Accountability to Children}

- Budget and resourcing: Ensure project funding for meetings and seed funding for child-led projects. Build the capacity of children's councils to generate resources locally to support initiatives.

- Representation: Children vote for their representatives, and all children irrespective of ethnicity and ability can have the opportunity to represent others.

- Training for children on soft skills: Working with media, public speaking, advocacy, graphic design, working with adults, project design, planning and implementing activities.

- Accountability: Feedback loops to ensure children know how adults and decision makers take their views into account.

- Sharing ideas and activities with the leadership: Children want to inform senior leadership and the board about their agenda.

- Organisational capacity building: Build group cohesion and ownership before taking on activities, campaigns, or meeting with leadership.

- Children as partners: Consider children as partners with ideas that are equally important to those of adults, otherwise you lose them from the very beginning.

I think the event that bring adults and children face-to-face, this is the best space. It is important because we have a lot of ideas and adults need to help us to implement them, and if you talk to them face to face, you tell them this is our problem and this is how we think, how to solve it. (Female adolescent member, CCC)

\section{Build Capacity of Adults and Young People}

Adults need to be prepared to share power, information, and space with children and young people, and genuinely listen to and consider their suggestions. Sensitisation of adults helps to ensure a common vision and shared understanding of the roles children can play in decision making. Capacity building is required to equip adults with the confidence, knowledge, personal values, and skills to respectfully communicate with and be influenced by children from diverse backgrounds (GenerationOn, 2010; World Vision, 2014). Field staff also require skills to support children's life skills, and the development and strengthening of their child groups (World Vision, 2017, 2019; see the case study below on Child Rights Connect's experience).

To effectively influence organisational decisions, children require child-friendly information about programme, strategies, and governance-where and how decisions are made. Young 


\section{Management and Accountability to Children}

people benefit from training in children's rights, effective communication, public speaking, advocacy, and ways to strengthen their own child groups (Eurochild 2017; World Vision, 2019). A young person from Peru explained, "[The organisation] has helped me to develop and be able to express my opinions. Participation . . . has helped me to loosen up, heal my emotions, and be able to express my ideas and opinions freely."

\section{Case Study: Children's Advisory Team Supported by Child Rights Connect (Global Child Rights Network)}

In 2018, Child Rights Connect set up a global Children's Advisory Team (CAT) of 21 children (aged 10 to 17), representing diverse contexts, who played a central role in the planning and implementation of the Day of General Discussion (DGD) on protecting and empowering Children as Human Rights Defenders (CHRD). Although many (not all) of the network's members are familiar with supporting children's participation, this was a key learning process for Child Rights Connect because it was the first time child participation had been initiated and directly supported by the network's Geneva-based Secretariat. Participants responded to an open public call on social media and through the network and were supported by members and partners to apply. Selection criteria were used to ensure that the final selection of participants was equal, fair, and inclusive.

Adult chaperones accompanied child representatives who travelled to Geneva for the DGD on CHRD. Adults and children received extensive briefings and trainings to enable them to engage meaningfully at the DGD and to keep everyone safe. Children were central to decision making at the DGD itself. They set and influenced its agenda, including the role of members of the committee, and Child Rights Connect members, in addition to informing the decision makers with their own presentations and views.

As a result of their participation:

- Ongoing feedback received by Child Rights Connect from children and network members (using a variety of formats) confirms that children feel empowered and motivated to influence decisions affecting them, and they continue to participate in their local contexts.

- Supporting children in the DGD proved to be an effective way of linking UN human rights mechanisms with children's local realities. It was also a strong way of bringing civil society together to share, learn, and collaborate.

- There is now a sense of urgency, responsibility, and commitment to empower children in all Child Rights Connect's work. It is now in the process of institutionalising child 


\section{Management and Accountability to Children}

participation not just at project level, but as a permanent structure in all aspects of its organisational decision making and governance.

- Child Rights Connect uses the CRC Committee's nine basic requirements to assess the quality of children's participation and improve based on their learning and the feedback from children.

- Network members, especially smaller organisations and those with limited experience of supporting children, have improved child participation in their own contexts at local and national levels, as a result of shared experience and learning.

\section{Lessons Learned}

- Involve children from the very beginning of the process.

- Ensure awareness of the process: Make sure that children and adults have awareness and understanding about the reasons why, who, how, where, and when children are participating.

- Assess existing governance structures and think creatively about ways to ensure children can be empowered in a meaningful and safe way: Do existing structures need to be adapted? How can children be empowered in this process, maybe they want to suggest different spaces that would also work for them?

- Be flexible and adapt: Children's participation is a step-by-step process that can be revised and updated along the way. There is no perfect model, but it is necessary to put time into focusing on the preparations, planning, and follow-up.

- Share experiences and learn from others: Involve experts when possible, and benefit from their experience.

\section{Focus on Inclusion and Child-Centered Mechanisms}

When working with existing community-based child groups, children have been encouraged to develop and/or apply selection criteria that support representation of children from diverse backgrounds in relation to gender, dis/ability, ethnicity, and school/working background. Not requiring English proficiency supported more inclusive participation opportunities. Furthermore, increased outreach with parents, caregivers, and communities is often required to ensure informed consent and local support for the participation of most vulnerable girls and boys (GenerationOn, 2010; More et al, 2018; World Vision, 2017). A young person from Peru explained: "In my organization we look for children from every background, there is no discrimination. We communicate via Facebook, there are boys and girls who live in more disadvantaged places, their parents support them, we try to look for those children." 


\section{Management and Accountability to Children}

Informal and formal spaces are needed for children to prepare in their peer groups and to dialogue with organisational leaders to influence organisational decisions that affect them. Structures such as child clubs, consultative committees, and school councils can provide important space for young people to regularly come together to discuss, prioritise, analyse, and action plan on these matters. Crucial efforts are required to ensure that children meet with the right people who have power to make decisions that are most relevant to them. A young person from Romania explained, "It is good when we meet adults that have status in society. We speak with them, and we tell them what we have to say, they hear us, and something is happeningproblems are resolved, or something is improved."

Further, strategies, structures, and processes to meaningfully engage children in organisational governance have been more effective when young people have opportunities to inform and influence the design of the model (Adolescent Health Initiative, 2014; Arunkumar et al., 2018; Collins et al., 2020; Save the Children, 2009; World Vision, 2013, 2016). When children have space and support to influence agendas and initiatives, it increases opportunities for child-led innovation. As one young person from Peru added, "There are also times when they have made decisions without consulting us. In this situation we dialogue and express our discomfort very appropriately and we fix these problems. I think there is a lot of trust with the [field] staff."

Children tend to be most motivated to participate in programming, strategy development, and advocacy when the process and activities are interesting, and when they are able to discuss and influence concrete matters and decisions (Charles \& Haines, 2019; Collins et al., 2020;

GenerationOn, 2010; O'Kane \& Barros, 2019; Tsang et al., 2020). Use of creative methods and tools, such as participatory appraisal tools (body mapping, ranking, problem trees), drama, and digital media can motivate and sustain children's engagement and can enhance children's analysis and communication skills (Charles \& Haines, 2019; Collins et al., 2020; O'Kane \& Barros, 2019; World Vision, 2019a). Opportunities to represent their peers in high-level meetings and advocacy initiatives are also a source of motivation and personal skill development.

\section{Children's Perspectives on the Decisions They Want to Influence}

In this section, key findings are presented from focus group consultations with young people in the Dominican Republic, Ghana, Palestine, and Romania and interviews with young people in 


\section{Management and Accountability to Children}

Peru, the Philippines, and Romania, concerning decisions they want to influence in World Vision, their reasons why, and how-to approaches to support their meaningful participation.

\section{Strategic Priorities and Plans}

Young people in Romania and Palestine emphasised their interest to influence national strategies-especially strategic priorities, annual planning, technical program plans, and project interventions. Young people from Peru and the Philippines highlighted the importance of dialogue between children and the managers and national director to influence programme developments on priority issues affecting young people in their communities. According to young people in Romania, they know better than anyone else what the top priorities are for them, what is missing in their lives, and what is keeping them from fulfilling their dreams.

Young people in each country highlighted the importance of opportunities to influence the design, planning, and implementation of programming on issues affecting them. For example, young people from Ghana emphasised the importance of their participation in child abuse prevention and management, including efforts to train community-based child protection members on the importance children's participation. Adolescent girls in Peru emphasised the need for girls to influence programming on sexual and reproductive health.

\section{Budget Allocations and Staff Recruitment}

Young people from Ghana, Palestine, and Romania explained that they would like to influence decisions on budget allocations, to ensure that budgets are allocated to child-focused and childled interventions. Young people in Ghana wanted budgets allocated to support the construction of safe schools and provision of information communication and technology facilities in schools to enhance learning. Children and young people are interested to have more information and training about how to develop budgets and monitor spending to ensure that funds are best used to address children's needs. Through such activities, children increase organisations' accountability to children and their communities.

Young people from Ghana, Palestine, and Romania also want to influence decisions about the recruitment of staff and volunteers to help select people who can positively interact with, encourage, and support children. Children can help create ideal profiles for staff who work with children. Young people from Peru and Romania emphasised the importance of having staff who are good at building trusting relationships with children. 


\section{Management and Accountability to Children}

\section{Capacity Building of Young People}

The study findings show that young people can inform plans and design of capacity-building and skill-building activities for children and young people to enhance personal development, active participation, and their abilities to defend their rights. Support to strengthen child-led entities are also important to help them develop inclusive, democratic structures. Children also expressed their desire to communicate and network with other young people to exchange and learn from one another, to reflect on their needs and achievements across countries and regions.

\section{The Importance of Influence}

Children gave many reasons on why it is important for them to influence the organisation's decisions:

1. Children are key actors and have rights.

2. Children know their own problems, priorities, and gaps to be addressed.

3. Children have good ideas and can be good role models.

4. Children can influence more relevant and effective strategies, programmes, and budget allocations.

5. Children can develop their knowledge and skills and lead innovations.

6. Children's perspectives should be integrated in community development.

7. Children can share feedback to inform monitoring and evaluation, and feedback to children is important to be accountable.

8. Children can help recruit good staff.

Furthermore, a child representative from Palestine mentioned:

We want decision makers to listen to our voice, address our needs, and implement projects in a way that suits and benefits children. . . . We can participate in the board of directors at the national level to influence their decisions for the benefit of children. We are the ambassadors of children's challenges, needs, and goals.

\section{Conclusion \& Recommendations}

The purpose of this landscape assessment was to identify common elements in different organisational models of child participation in governance; challenges to children's participation in decision making, including adult mindsets, low capacity, and structural restrictions; lessons learned on enabling factors, such as organisation-wide buy-in, and space and inclusion for 


\section{Management and Accountability to Children}

young people; and children's perspectives on decision making. The landscape resulted in several recommendations for the commissioning organisation, generalised to the sector. These recommendations provide practical pathways to operationalise Lundy's model for child participation, based on examples from programming and experience of practitioners and children themselves:

1. Ensure child participation has high-level organisational commitment, organisation-wide buy-in, senior leadership endorsement, and management oversight and accountability (Elsley \& Tisdall, 2014).

2. Ensure clarity of purpose and scope of accountability to children.

3. Build upon existing good practice, processes, and structures, moving from local to global, ensuring participation permeates all spaces rather than being treated as standalone activities (O'Sullivan, 2019).

4. Increase investments in staff capacity building on children's participation, including increased budget allocations to support participation (Lundy, 2018; Tisdall, 2015).

5. Build children's capacities and strengthen child-led networks, including co-design and planning with children and other forms of transformative participation (Tisdall, 2013).

6. Reflect, document, learn, exchange, and adapt with children. (See full Recommendations in Appendix 1.)

There is a need for further inquiry on both the purpose and the appropriateness of children and young people's involvement in governance; understanding which decisions they want to influence to avoid creating space for space's sake; as well as understanding and setting the parameters, legal and otherwise, for their involvement in high level governing bodies. It may not be feasible or appropriate to have children as members of boards of directors, but consulting, collaborating, and listening to children and young people can help these bodies reflect a more robust and inclusive oversight.

\section{References}

Adolescent Health Initiative. (2014). Creating and sustaining a thriving advisory council: A collection of youth experiences and recommendations compiled by the Adolescent Health Initiative. University of Michigan Adolescent Health Initiative. https://www.umhs-adolescenthealth.org/wpcontent/uploads/2017/02/manual-for-website.pdf

Arunkumar, K., Bowman, D. D., Coen, S. E., El-Bagdady, M. A., Ergler, C. R., Gilliland, J. A., Mahmood, A., \& Paul, S. (2018). Conceptualizing youth participation in children's health research: Insights 
Journal of Youth Development | http://jyd.pitt.edu/ | Vol. 16 Issue 2-3 DOI 10.5195/jyd.2021.1045

Management and Accountability to Children

from a youth-driven process for developing a youth advisory council. Children (Basel, Switzerland), 6(1), 3. https://doi.org/10.3390/children6010003

Blanchet Cohen, N., \& Torres, J. (2015). Accreditation of child friendly municipalities in Quebec:

Opportunities for child participation. Children, Youth and Environments, 25(2), 16-32.

https://doi.org/10.7721/chilyoutenvi.25.2.0016

Charles, A., \& Haines, K. (2019). Engaging young people as partners for change: The UR Community project. International Journal of Children's Rights, 27, 140-175.

https://doi.org/10.1163/15718182-02701007

Collins, T.M., Jamieson, L., Wright, H.V., Rizzini, I., Mayhew, A., Narang, J., Tisdall, K.M., \& Ruiz-Casares, R. (2020). Involving child and youth advisors in academic research about child participation: The Child and Youth Advisory Committees of the International and Canadian Child Rights Partnership. Children and Youth Services Review, 109(C). https://doi.org/10.1016/j.childyouth.2019.104569

Elsley, S., \& Tisdall, K. (2014). Young people's participation in policy-making: Sharing practice. University of Edinburgh Centre for Research on Families and Relationships.

http://www.crfr.ac.uk/assets/Participation-briefing-2.pdf

EuroChild. (2017). Child participation strategy.

https://www.eurochild.org/fileadmin/public/03 Internal/04 Members Room/Eurochild Child Part icipation Strategy.pdf

Gruber, A., \& Gyurko, S. (2018). Facilitators manual: Guidelines to enhance child participation and work with youth on children's advisory boards. International Juvenile Justice Observatory. https://www.oijj.org/en/away-facilitatorsmanual

Hinton, R. (2008). Children's participation and good governance: Limitations of the theoretical literature. The International Journal of Children's Rights, 16(3), 285-300. https://doi.org/10.1163/157181808X311141

GenerationOn. (2010). Game changers: Establishing a youth advisory council. Youth Power. https://www.youthpower.org/sites/default/files/YouthPower/resources/game changers yac toolk it.pdf

Kennan, D., Brady, B., \& Forkan, C. (2019). Space, voice, audience and influence: The Lundy model of participation (2007) in child welfare practice. Practice Social Work in Action, 31(3), 205-218. https://doi.org/10.1080/09503153.2018.1483494

King, N., \& Brooks, J. M. (2017). Template analysis for business and management studies. London: Sage. https://us.sagepub.com/en-us/nam/template-analysis-for-business-and-managementstudents/book244282\#description 
Journal of Youth Development | http://jyd.pitt.edu/ | Vol. 16 Issue 2-3 DOI 10.5195/jyd.2021.1045

Management and Accountability to Children

Lansdown, G., \& O'Kane, C. (2014). A toolkit for monitoring and evaluating children's participation. Save the Children UK. https://resourcecentre.savethechildren.net/document-collections/toolkitmonitoring-and-evaluating-childrens-participation

Lundy, L. (2007). Voice is not enough: Conceptualising Article 12 of the United Nations Convention on the Rights of the Child. British Educational Research Journal, 33(6), 927-942. https://doi.org/10.1080/01411920701657033

Lundy, L. (2018). In defense of tokenism? Implementing children's right to participate in collective decision-making. Childhood, 25(3), 340-354. https://doi.org/10.1177/0907568218777292

More, T., McArthur, M., \& Noble-Carr, D. (2018). More a marathon than a hurdle: towards children's informed consent in a study on safety. Qualitative Research, 18(1), 88-107. https://doi.org/10.1177/1468794117700708

O'Kane, C., \& Barros, O. (2019). It's Time to Talk! Children's views on children's work: Lessons learned from a global participatory research project. It's Time to Talk. https://www.time-to-talk.info/wpcontent/uploads/2019/05/Lessons-Learned-FINAL-1.pdf

O' Sullivan, J. (2019). Children's right to be heard: Identifying the barriers and enablers within a primary school context. Children's Research Network Research Digest.

https://www.researchgate.net/publication/333717980 Children's Right to be Heard Identifying the Barriers and Enablers Within a Primary School Context

Save the Children UK. (2009). Global Children's Panel 2009: Learning points and next steps.

Save the Children UK. (2010). Global Children's Panel Meeting 2010: Lessons learnt and recommendations.

Theis, J. (2007). Performance, Responsibility and political decision-making: Child and youth participation in Southeast Asia, East Asia and the Pacific. Children, Youth and Environments, 1入1), 1-13. http://www.jstor.org/stable/10.7721/chilyoutenvi.17.1.0001

Tisdall, E. K. M. (2013). The transformation of participation? Exploring the potential of 'transformative participation' for theory and practice around children and young people's participation. Global Studies of Childhood, 3(2), 183-193. https://doi.org/10.2304/gsch.2013.3.2.183

Tisdall, E. K. (2015). Addressing the challenges of young people's participation: Considering time and space. In T. Gal \& B. F. Duramy (Eds.), International perspectives and empirical findings on child participation: From social exclusion to child-inclusive policies (pp. 381-404). Oxford University Press. https://doi.org/10.1093/acprof:oso/9780199366989.001.0001

Tsang, V. W. L., Chew, S. Y., \& Junker, A. K. (2020). Facilitators and barriers to the training and maintenance of young persons' advisory groups (YPAGs). International Journal of Pediatrics and Adolescent Medicine, 74 ), 166-173. https://doi.org/10.1016/j.ijpam.2019.10.002 
Journal of Youth Development | http://jyd.pitt.edu/ | Vol. 16 Issue 2-3 DOI 10.5195/jyd.2021.1045

Management and Accountability to Children

UNICEF. (2020). Engaged and heard! Guidelines on adolescent participation and civic engagement. https://www.unicef.org/media/73296/file/ADAP-Guidelines-for-Participation.pdf

World Vision. (2014). Research study: What next? Ways forward for children and young people's participation.

World Vision, (2015). Children and young people's participation: Strategic direction 2015-2020.

World Vision. (2016). Child-friendly feedback mechanisms: A case study from Mongolia.

World Vision. (2017). Leading the way: Guidance on the participation of young people in global engagements.

World Vision. (2019). Children's feedback mechanisms: Helping children to hold World Vision to account at the programme, national office and partnership levels.

World Vision Bangladesh. (2018). Concept note: Child participation in organisational decision-making.

World Vision Romania. (2013). From the community to the board room: Creating an organisational culture of listening to young people: A case study on World Vision Romania and the Children's Consultative Council. Author.

Wyness, M. (2009). Adult's involvement in children's participation: Juggling children's places and spaces. Children and Society 23(6), 395-406. https://doi.org/10.1111/j.1099-0860.2008.00181.x 


\section{Appendix 1}

\section{Full Recommendations from the Landscape Assessment for World Vision International}

\section{Ensure high-level organisational commitment and organisation-wide buy-in to embed children's participation in our DNA}

As a child-focused organisation, there is a child rights imperative to ensure that organisational policies, standards, processes, and budgets are in place to demonstrate respect for the rights of children to be heard in decisions that affect their lives. Children's representatives participating in the Triennial Council have asked World Vision to make greater efforts to

- Incorporate the input of children and young people in decision making at National Office Board Meetings and governance (2016).

- Establish children's consultative councils at the national and global level to ensure they can provide views and opinions on issues relevant to them (2019).

Children and young people involved in this study reinforced and elaborated upon these recommendations. To ensure high-level organisational commitment and organisation-wide buy-in to embed children's participation in organisational DNA necessitates an organisational culture that builds capacities and processes to engage children meaningfully in decisions that affect their lives. It requires

- a clear and shared vision from senior leadership;

- a formal mandate from the president;

- the development of a strategy and operational plan with allocated resources (human, financial, material) considering sustainability from the outset;

- the establishment of a cross-organisation-wide steering team including senior managers; 


\section{Management and Accountability to Children}

- management oversight and accountability, including staffing time to facilitate and coordinate efforts across the partnership;

- investments in staff preparation and training to ensure intentional and consistent efforts at all levels to create spaces for leadership to hear from children and their experience of programming at the community level;

- development and dissemination of child-friendly information and materials; and

- investments in capacity building of children and young people, with particular efforts to engage and build the capacity of the most vulnerable.

\section{Ensure clarity of purpose and scope}

To design an appropriate strategy and operational plan to support children's participation in organisational programming, management, and governance, it is essential to have clarity of purpose and scope. This is important to make the most effective use of available resources (human, material, and financial), including consideration of children's and staff's limited time availability.

Clarity is required to ensure that children and young people have genuine opportunities to influence decisions affecting them. This requires further analysis and planning with children and young people in regional and national contexts to identify decisions that are most relevant to them. It also requires further analysis of governance and power dynamics to ensure that children and young people meet with the right people. For instance, if board members have more of a good governance role, rather than a decision-making role in relation to developing strategic priorities, programmes, and

\section{We request World Vision to carry out a mapping of their decision-making spaces to make clear where children can and should give their opinion, so that they are included in all processes. (Children's representatives, Dominican Republic)}

plans, it is necessary for children to have opportunities to influence staff members who may have more say in such decisions. 


\section{Build upon existing good practice processes and structures at local and national level moving from local to global}

Children's participation in management and governance should build upon the foundations of quality participatory programming, and existing child-friendly accountability mechanisms. To enhance local ownership, cultural relevance, and sustainability it is important to build upon existing good practices and structures at the local and national levels such as community-based child clubs, children's congress, children's and young people's networks, etc. For example, the establishment of Children's Consultative Committees could build upon existing local child clubs and networks, while ensuring reflective action-oriented efforts by children and adults to ensure inclusive and equitable representation.

- Ensure meaningful participation of children and young people in all programming. Children and young people have emphasised the importance of having more space to inform and influence situation assessments, programme design, planning, implementation and monitoring, and evaluation. This also requires the development and dissemination of child-friendly information, and efforts to seek feedback from children and ensure feedback to them in every project.

- Strengthen and support quality implementation of children's feedback mechanisms (CFM) in all countries. The mechanism may also be strengthened to support children to develop and submit "alternative reports" to management.

- Identify four to six countries to pilot support for national- and/or arealevel Children's Consultative Committees, drawing upon existing good practices in community-based child clubs/groups/committees and wider child and youth networks with explicit efforts to involve disadvantaged children and young people.

- Ensure formal opportunities, scheduled feedback, reporting or listening space within existing structures or processes, as well as informal spaces for Children's Consultative Committees to engage with 
leadership and Board members which encourage informal dialogue and exchange. Opportunities for children to meet with national directors, senior leaders and board members in informal spaces provides greater opportunity for dialogue and exchange among children and adults, rather than expecting a couple of children's representatives to participate in formal Board meetings. Wider numbers of children and young people could also be supported to feed into child friendly reports (including video reports) to share their feedback with senior managers and board members. Furthermore, opportunities to identify and appoint official "children's friends" among adults in existing boards at national and global level can also support opportunities for children's views and priorities to influence management and governance decisions affecting them. ${ }^{3}$

\section{- Continue to support children's participation and representation in the} global meetings while ensuring linkages between national level Children's Consultative Committees and broader feedback gained from children across each country through the Children's Feedback Mechanism.

- In each of these processes use the nine basic requirements for effective and ethical participation, ensuring that it is

i. transparent and informative,

ii. voluntary,

iii. respectful,

iv. relevant,

v. child-friendly,

vi. inclusive,

vii. supported by training,

viii. safe and sensitive to risk, and

ix. accountable.

This is essential to ensure ethical practice, ensuring informed assent and consent by children and their caregivers, inclusive non-discriminatory practice, risk assessment

\footnotetext{
3 The Concerned for Working Children in India's experience of "Makala Mitra" is a good practice, whereby children identify "Children's friends" - adult allies who officially become "makala mitra" help them get more space and influence.
} 


\section{Management and Accountability to Children}

and safeguarding, and feedback to children. It is also essential to plan for sustainability. Consider how children stay engaged during (and after) their participation? How will they share their skills with their successors? What role will they have in recruiting others?

\section{Increase investments in staff and staff capacity building on children's participation to create a child friendly enabling environment.}

Increase investments in child participation advisors at different levels to support organisational wide capacity building of staff and volunteers. Sensitisation and

Adult capacity needs to be in place. l've met leaders who don't understand the importance of listening to children. (INGO, senior manager).

training on what constitutes meaningful participation is required for all board members, national directors, senior leaders and field staff.

The development and use of online training resources on children's participation can complement face to face briefings and mentoring. Field staff would benefit from training in effective communication, facilitation and community mobilisation skills, child friendly participatory tools, as well as organisational skills to support children and young people in strengthening their own child-led organisations and initiatives. It is also necessary to engage and sensitise children's parents, caregivers, community elders etc., so that they allow and support the participation of children and young people - especially the most vulnerable, including children with disabilities, out-of-school working children, ethnic minority girls, etc.

\section{Build children's capacities and strengthen child-led organisations and networks.}

Capacity building of children and young people, especially the most vulnerable is important to empower children with the skills, knowledge, and confidence to express their

Whenever possible start to build the capacity of children at young ages, around 10 years so that they can be part of child participation governance for a longer period (WV staff, Romania) views and suggestions. Sincere 


\section{Management and Accountability to Children}

efforts are required to develop and disseminate child-friendly information on issues, policies, and decisions affecting children. Efforts to support children and young people to come together regularly in their own groups-including age and gender-specific groups can enhance opportunities for exchange, reflection, and peer learning.

Capacity building of children on child rights, life skills, gender and disability inclusion, public speaking, advocacy, and digital technologies can equip children with increased knowledge and skills to assert and defend their rights. Investments in appropriate (online) tools can maximise opportunities to collaborate remotely where necessary, taking efforts to ensure children representing marginalised groups are included. Furthermore, use of the Article 15 toolkit can help members of children's groups reflect and strengthen their own child-led groups and initiatives.

Support and strengthening of children's networks enhance opportunities for peer learning, exchange, and collective advocacy. Networks also provide platforms for election and representation among children and young people at higher levels. Networks of children and young people can cut across groups supported by different agencies and can link to broader platforms for children and young people to influence external governance processes affecting them.

\section{Reflect, document, learn, exchange and adapt with children}

Most important is to start systematic efforts to support children and young people's participation in organisational decision making and to reflect, document, and learn with children, staff, and communities. Flexibility and

Trial and error is the way to go... I think a constant process of self-reflection will help get a good result, especially if we focus on how to do this at a high level... Be courageous to try. (INGO manager) adaptive learning are crucial, so that improvements can be made along the way.

The inter-agency toolkit to monitor and evaluate children's participation can be used to inform monitoring and evaluation of the scope, quality, and outcomes (Lansdown \& O'Kane, 2014) and establishing feedback mechanisms with and for children during the planning phase should be prioritised. 
Journal of Youth Development | http://jyd.pitt.edu/ | Vol. 16 Issue 2-3 DOI 10.5195/jyd.2021.1045

Management and Accountability to Children

\section{Appendix 2}

\section{NVivo Coding Template and Node Structure}

\begin{tabular}{|c|c|c|}
\hline \multicolumn{3}{|l|}{ Nodes } \\
\hline Name & Sources & References \\
\hline T1. WV ORGANISATION & 15 & 50 \\
\hline 2.SPACE & 41 & 249 \\
\hline (7) i) KEY ELEMENTS & 30 & 122 \\
\hline ii) PROCESS GET STARTED & 25 & 92 \\
\hline iil) CYP INVOLVED IN DESIGN & 14 & 22 \\
\hline$\boxplus \bigcirc$ iv) CONVINCE RESISTANCE & 8 & 11 \\
\hline 3.OPPORTUNITIES & 39 & 236 \\
\hline † i) WHICH CHILDREN & 26 & 67 \\
\hline ii) DISADVANTAGED BACKGROUNDS & 18 & 24 \\
\hline iii) COME TOGETHER IN MEETINGS & 20 & 29 \\
\hline iv) AGENDA & 15 & 28 \\
\hline$+\bigcirc$ v) ACTIVITIES & 20 & 57 \\
\hline +. vi) CONSULTATIVE, COLLABORATIVE, CHILD LED & 10 & 12 \\
\hline+ vii) DIALOGUE WITH ORG DEC-MAKERS & 4 & 7 \\
\hline Ð viii) LINKAGES at different levels & 9 & 12 \\
\hline 4. CAPABILITIES & 35 & 148 \\
\hline (T) i) INFORMATION & 13 & 19 \\
\hline ii) FINANCIAL \& HUMAN RESOURCES & 11 & 24 \\
\hline (†) $\mathrm{ii)}$ TRAINING & 25 & 65 \\
\hline (T) 9 BASIC REQUIREMENTS & 14 & 19 \\
\hline (iv) SAFEGUARDING & 15 & 21 \\
\hline 5. INFLUENCE & 40 & 210 \\
\hline i) CHILDREN INFLUENCE DECISIONS & 27 & 51 \\
\hline$\bigoplus$ ii) TYPES OF DECISIONS & 12 & 100 \\
\hline † iii) HOW ADULTS LISTEN & 10 & 20 \\
\hline iv) AREAS OF GOVERNANCE NOT RELEVANT & 8 & 11 \\
\hline$\oplus \bigcirc$ v) FEEDBACK MECHANISMS & 16 & 23 \\
\hline 6. LESSONS LEARNED & 45 & 368 \\
\hline (i) WHAT WORKS WELL \& ENABLING FACTORS & 38 & 175 \\
\hline ii) CHALLENGES \& HINDERING FACTORS & 35 & 141 \\
\hline + iii) SCALE UP \& SUSTAINABILITY & 13 & 25 \\
\hline$\boxplus \bigcirc$ iv) FINANCIAL \& HUMAN RESOURCES & 10 & 27 \\
\hline 7. MONITORING & 22 & 63 \\
\hline 8. RECOMMENDATIONS & 36 & 350 \\
\hline 9. OTHER COMMENTS & 5 & 6 \\
\hline
\end{tabular}

